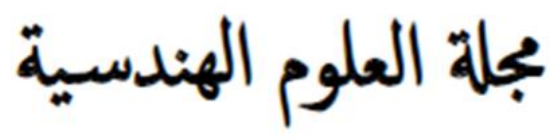

FES Journal of Engineering Sciences

\title{
Quality Control of Pre-stressed Concrete Sleepers in Sudan Railways
}

\author{
Ali Hussein Mohamed Ali ${ }^{1, *}$, and Abubaker Barakat Babiker Barakat ${ }^{2}$
}

1 Civil Engineering Department, University of Bahri, Khartoum, Sudan

2 Civil Engineering Department, University of Khartoum, Khartoum, Sudan

* Corresponding author: Ali Hussein Mohamed Ali (e-mail: alibass288@hotmail.com).

Article history: Received 11 March 2020, Received in revised form 4 November 2020, Accepted 11 November 2020

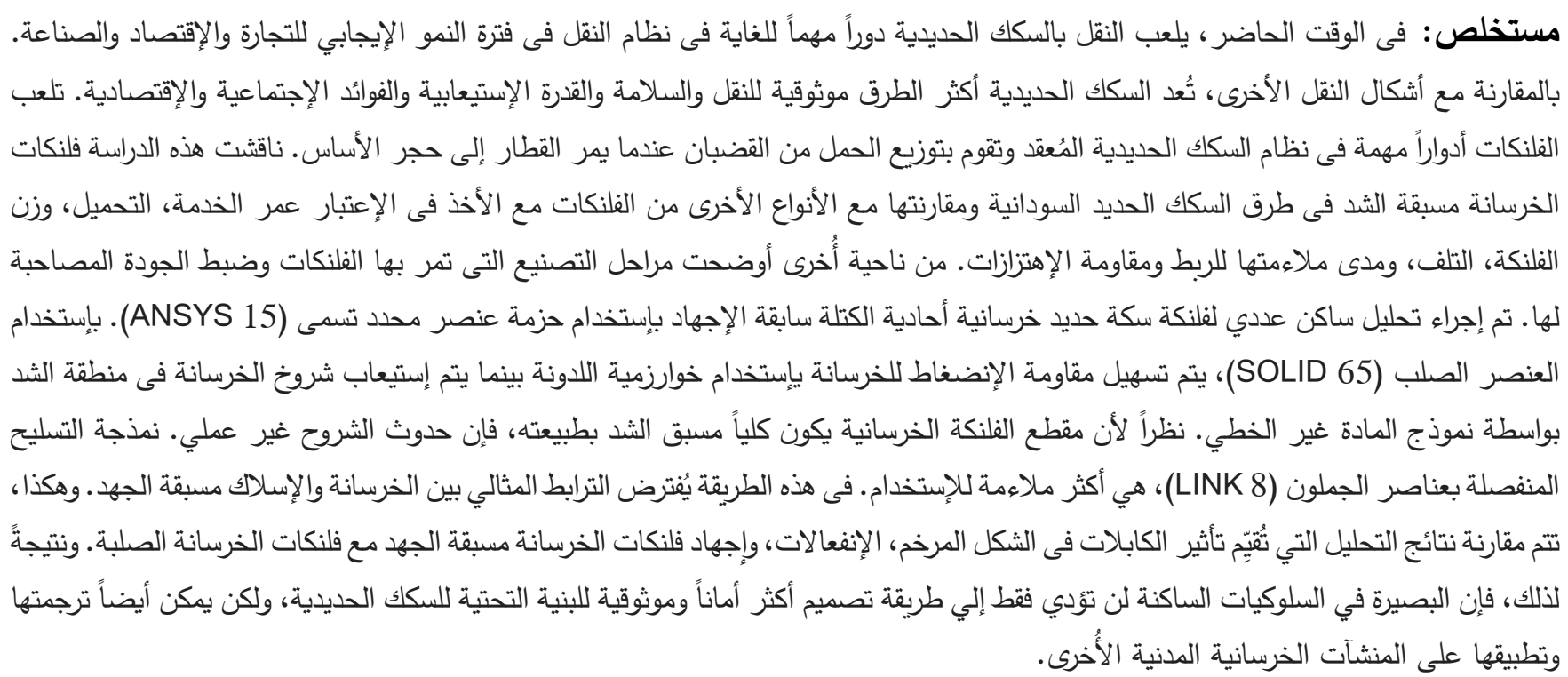

ABSTRACT Nowadays, railway transport plays a very important role in the transport system in a period of positive growth of commerce, economy and industry. In accordance with other modes of transport, railway is the most stable mode for transporting, safety, capability carrying, social and economic benefits. Sleepers have major roles in the complex railway system and distributed the load from rails when train goes through to the ballast. This study discussed pre-stressed concrete sleepers in Sudan railways and compare them with other varies of sleepers taken in consideration the service life, handling, weight of sleeper, damage, suitability for fastening and vibration resistance. On the other side explained the manufacturing stages that sleepers undergoes and the quality control accompanying them. A numerical static analysis for a pre-stressed concrete mono-block railway sleeper is carried out using finite element package named "ANSYS 15". Using SOLID65 solid element, the compressive strength of concrete is facilitated using plasticity algorithm while the concrete cracking in tension zone is accommodated by the nonlinear material model. Since the section of concrete sleeper is fully pre-stressed by nature, the smeared crack analogy is impracticable. Discrete reinforcement modeling with truss elements, LINK8, is then more suitable to utilize. Perfect bonding is presumed herein between concrete and pre-stressing wires. Thus, the results of the analysis that evaluate the effect of cables in deformed shape, strains, stress of pre-stressed concrete sleepers are compared to the solid concrete sleepers. Therefore, the insight into static behaviors will not only result in a safer and more reliable design method for railway infrastructure, but it can also translate and apply to other civil concrete structures.

Keywords: ANSYS 15, finite element, numerical analysis, Pre-stressed concrete sleeper, railway track, solid concrete sleeper, and static load. 


\section{INTRODUCTION}

Railway sleepers are the components on which the rail with the right gauge are arranged. These sleepers generally rest on ballast and are often referred to some regions as ties. These sleepers take the load from the rails when the train passes and distribute it to the Ballast.

Railway tracks are constructed to carry passengers or goods through regions. The track structures are required to direct and allow any activity to be safe, cost-effective and smooth. Figure 1 shows the main components constituting typical railway tracks. Its components can be subdivided into the two major groups: superstructureand substructure.

Category known as the superstructure forms $t$ he most visible components of the track, such as $r$ ails, rail pads, concrete sleepers, and fastening sys tems. The substructure is connected with a ballast, sub-ballast and sub-grade geotechnical system (formation). Both the superstructure and the substructure are equally critical in maintaining the protection and comfort of railway tracks used to distribute the axle load on tracks from the rails to the base system., while the word' railway sleeper 'is often referred to in the US and Canada as' railroad tie' [1].

Railway sleepers are the cross-tie beams resting on ballast and support. Wooden sleepers were used back in the past for their higher growth and longer operating life than concrete and steel materials. Pre-stressed concrete (PC) sleepers and, to a minor extent, steel sleepers have been used worldwide in modern railway tracks for their greater longevity and longer operating life than concrete and steel materials. Wooden sleepers were used back in the past. Pre-stressed concrete (PC) sleepers and steel sleepers have been used worldwide on modern railway tracks to a limited degree [2].

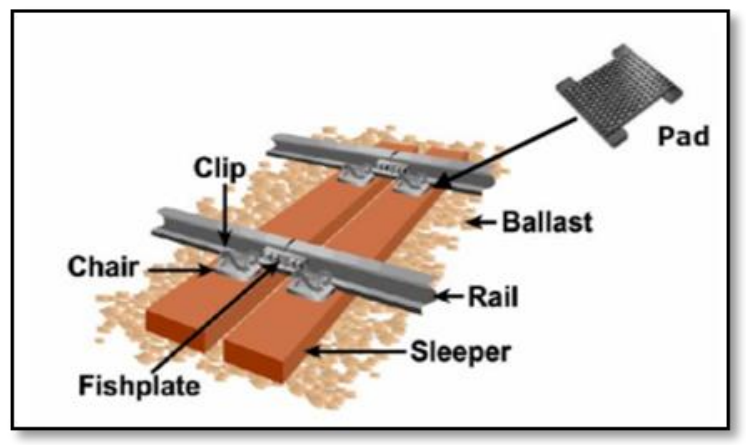

Figure 1. Typical railway Track.

\section{$>$ Research problem:}

In recent years some of trains in Sudan Railways slide out of track service and makes accidents resulting for many timber sleepers are susceptible to fire, rotting and someone useful life is end. There are various solutions for this problem such as steel sleepers, pre-stressed concrete sleepers.

All types of sleepers had proven their capability to solve many problems but the cost and durability play an important role in determining the best option. Pre-stressed concrete sleepers do not rot and extra weight makes the track more stable (especially with temperature changes), they are better able to withstand fire hazards than wooden sleepers, they give the track more reliably, they have a longer life and need less maintenance than wooden sleepers.

\section{LITERATURE REVIEW}

\subsection{General}

The railway track or permanent road is called the combination of rails, fitted on sleepers with an ap propriate

Fastening system and resting on ballast and subg rade.

Sometimes, as shown in Figure 2, temporary track $s$ are often laid for earth and material conveyance during construction works [2].

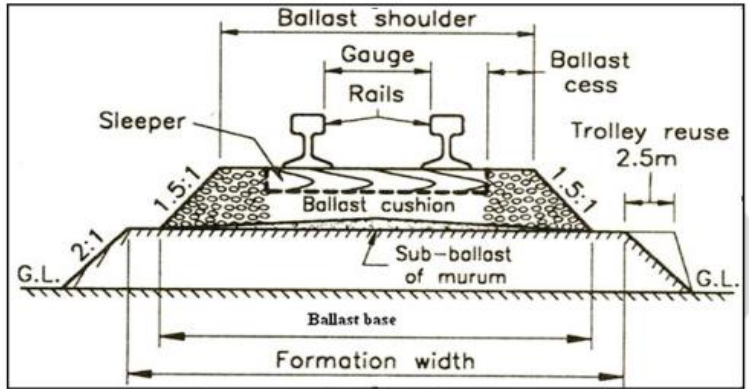

Figure 2. Typical cross-section on the embankment of a permanent road.

The rails are permanently linked in series by fish plates and bolts and then connected to sleepers by various means of fastenings. The sleepers properly spaced, resting on the ballast are suitably loaded with ballast. On the prepared subgrade, called the formation, the layer of ballast rests.

To transfer the wheel load to the sleepers, the rail $\mathrm{S}$

Serve as girders. In terms of proper tilt, gauge an $\mathrm{d}$ level, the sleepers keep the rails in the correct $\mathrm{p}$ osition and 
Transmit the load from the rails to the ballast. The load is distributed by the ballast over the formati on and the sleepers are kept in place.

For the purpose of carrying axle loads, the rails on the track act as steel girders. They are made of high-carbon steel for wear and tear resistance. Rail roles include a rigid, smooth and unchanging surface with minimal friction between steel rails and steel wheels for the movement of heavy moving loads, bearing the stresses of heavy vertical loads, lateral and braking forces and thermal stresses and transmitting loads to sleepers [2].

The most important function of fastening systems is to provide a powerful and flexible connection between thesleeper or slab rail and its supporting structure. Two main forms of fastening are available: rigid and elastic. Rigid fastenings are distinguished by the early growth of the bullhead rail in chairs, are costly rigidly bolted to systems, do not have the required durability when used with concrete sleepers and have been replaced by newer, elastic fastening systems [3].

The main purpose of the rail pad is to spread the contact load from the rail to the sleeper. The rail pad also has an important role to play in attenuating impact loads from bad joints, track irregularities and faults in rolling stock. The pads must stay in place and not work out in use, and, like the insulator, must not degrade in normal use. Pads are made typically of rubber, rubber bonded cork, high density polyethylene (HDPE), polyurethane and ethyl vinyl acetate (EVA). Pad thicknesses vary between $5 \mathrm{~mm}$ and $10 \mathrm{~mm}$. Pad stiffness is typically in the range $100 \times 103 \mathrm{~N} / \mathrm{mm}$ to $600 \times 103 \mathrm{~N} / \mathrm{mm}$. On heavy passenger railways the elastic behavior of the pad is of less significance than for track where the speed exceeds $100 \mathrm{~km} / \mathrm{h}$. Therefore durability is the overriding requirement and plastic materials such as EVA are used. HDPE becomes brittle at low temperatures and so is not suitable for use in freezing conditions [4].

\subsection{Sleepers}

Sleepers are members primarily laid transverse to the rails on which the rails are supported and positioned in order to move the loads to the ballast from the rails and subgrade below. Sleepers perform the following basic functions.
Transfer and distribute loads equally from the rail foot to the underlying ballast bed.

Sustain and preserve the rails at the right gauge by controlling the rail fastening system anchorage. Preserve rail inclination.

Providing rail support by limiting the movement of longitudinal, lateral and vertical rails Reduce the vibrations coming from rails.

To keep the rails in the correct degree of transverse tilt, i.e. the level of turnouts, crossovers, etc., and in straight tracks at 1 in 20 tilt, in order to provide rails with a firm and even support.

To act as elastic medium in between the ballast and rails.

An ideal sleeper should have the following characteristics for good sleeper performance to fulfill the above functions or objectives.-

The sleepers to be used should have minimal initial and maintenance costs.

The fittings of the sleepers should be such that they can be easily modified during maintenance operations such as essential lifting, packing, removal and replacement.

The weight of the sleepers should not be too high or too low for ease of handling, i.e., they should have a moderate weight. The design of the sleepers should be such that it is simple to change and maintain the gauge, track orientation and level of the rails.

The bearing area of the sleepers under the rail seat and over the ballast should be sufficient to resist the crush due to the rail seat and crushing of the ballast under the sleeper. The sleeper design should be such as to facilitate easy removal and replacement of ballast.

The sleepers should be able to endure shocks and vibrations due to the passage of heavy loads from the high-speed limits.

During packing procedures, the configuration of the sleepers should be such that they are not harmed.

\section{3: History}

Canadian National Railways (CNR) installed a few reinforced concrete sleepers into track in the 1920s [5].

In the USA the first recorded use of concrete sleepers was in 1893 when 200 were installed by the Reading Company in Germantown, 
Pennsylvania. The first use of pre-tensioned concrete sleepers in the USA was in 1960 when 500 were installed on the Atlantic Coastline Railroad and 600on the Sea board Airline Railroad, followed by 600,000 sleepers on the combined Seaboard Coastline Railroad [5].

South African Railways (SAR) started testing small numbers of proprietary concrete sleepers from 1945 to 1952 in 1956 deliveries of the first sleepers.

The full length post-tensioned mono-block sleepers were not introduced until 1963, as part of a limited test in 1957. The manufacture of twin-block sleepers ended in 1967. SAR was implemented in 1964 with the short line pre-tensioned system and in 1970 with the long line process [5].

After a series of trials during 1967, the growth of concrete sleepers in India began, then initial designs adopted $4 \mathrm{~mm}$ or $5 \mathrm{~mm}$ plain high tensile steel wires as tendons.

Experiments in Japan with mono-block and twin-block concrete sleepers in the 1950s led to the adoption of pre-stressed concrete mono-block sleepers on narrow lines and for new standard gauge lines.

One of the longest railways in Africa is the Sudan Railways. It operates $4,180 \mathrm{~km}$ of $1,067 \mathrm{~mm}$ gauge (narrow gauge) single line. In 1897, during the Anglo-Egyptian Condominium, building of railway lines began and most of the track was constructed before 1930. Since 1995 SRC started communication with Chinese companies, resulted in signing and implementing of several contracts mainly in the field of supplying new main line locomotives, freight, Wagons, rail, bogies, DMU units, Construction of new track and maintenance services with total amount of 1,287.47 million USD. These companies began to rehabilitate railway in 2000 by establishing the factory of concrete sleepers in Atbara city but many factors affect this not to complete until 2010. HIBO Company began to produce pre-stressed concrete sleepers in January 2011.The factory is constructed to produce 2000sleepers/day which were enough to rehabilitate $450 \mathrm{~km} /$ year.

\subsection{Classification of railway sleepers}

Based on the materials used [see Figure 3], railway sleepers are classified into following types [4].
1. Wooden sleepers.

2. Concrete sleepers.

3. Steel sleepers.

4. Cast iron sleepers.

5. Composite sleepers.

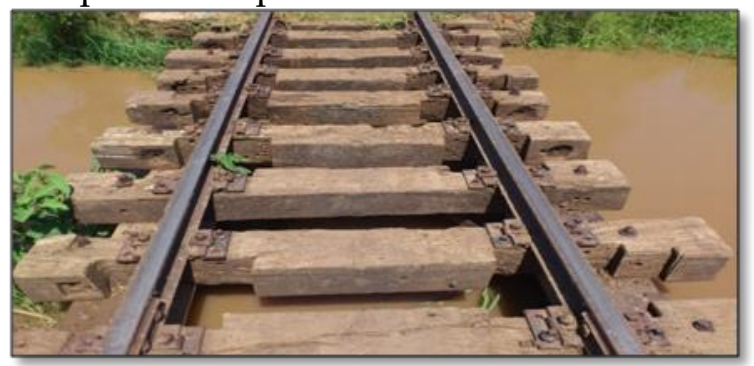

(a) Wooden Sleepers.

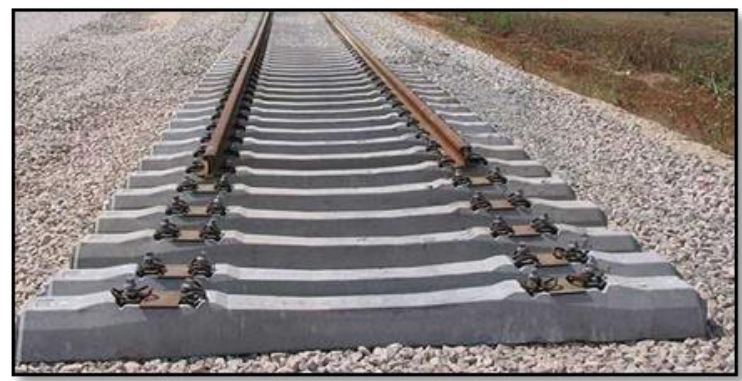

(b) Concrete Sleepers.

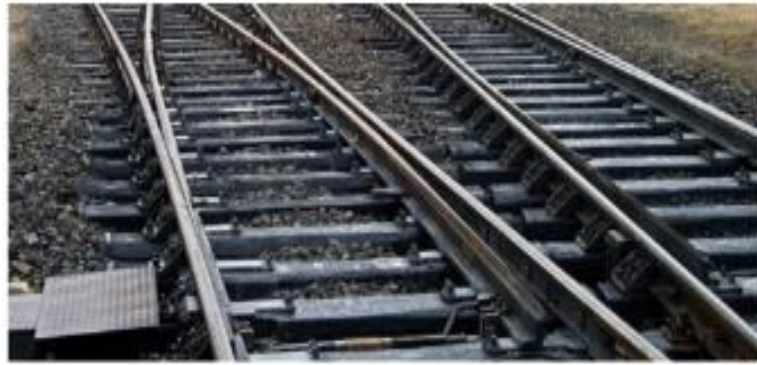

(c) Steel Sleepers.

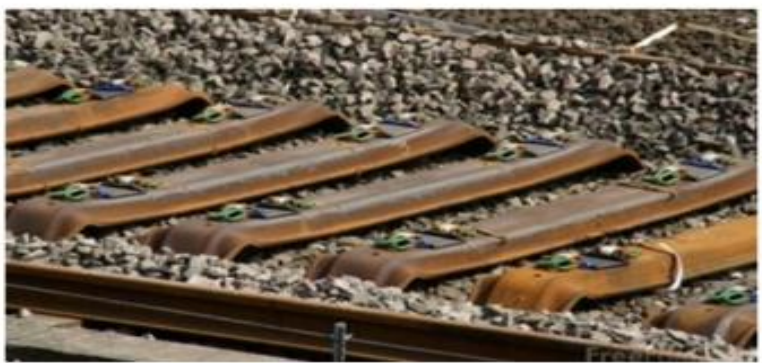

(d) Cast iron Sleepers.

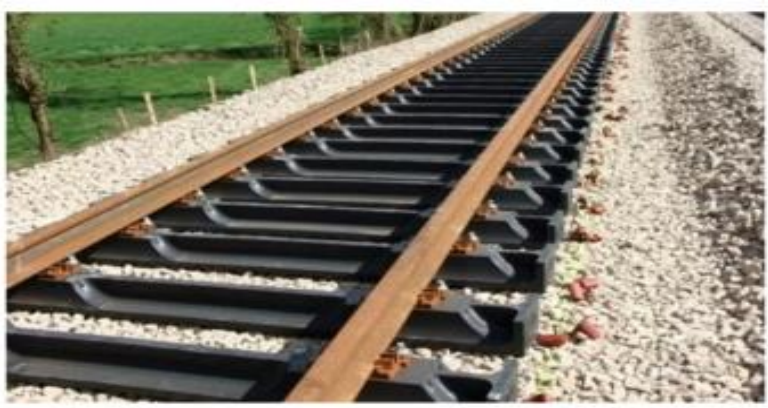

(e) Composite Sleepers.

Figure 3. Types of Railway Sleepers. 


\subsection{International Standards}

A specification (\# 710) for concrete sleepers has been issued by USC, the international railway union. Various standards such as Australian Standards, AS 1085.14:2012 (Railway Track Material Pre-stressed Concrete Sleepers), or EN 13230-4:2016 (Railway Applications-Track Concrete Sleepers and Bearers) are used in other countries, such as Malaysia and Singapore. Part 4: Transfer and Crossing Pre-stressed Bearers). As a supplementary guide, the UIC 713R leaflet is also used because of Part 6 of EN 13230,

\section{MANUFACTURING AND QUALITY CONTROL}

Manufacturing methods can be grouped under three types: long-linefor pre-tensioned, fully bonded, mono-block sleepers; short-linefor pre-tensioned, fully bonded and end-anchored mono-block sleepers; or instant demouldingfor twin-block reinforced concrete sleepers and post-tensioned mono-block sleepers [5].

The concrete sleepers, many sleepers long, are made upside down in moulds. Inserted into the molds are Pandrol clip bases or other fittings. Pre-stressed steel reinforcing bars are fitted into these moulds, and then the concrete is poured. It takes several days for the concrete to recover, after which the sleepers are removed from the molds and cut into individual sleepers.

The lower part of the mould is marked with the manufacturer's logo and a date stamp. Occasionally, sleepers are manufactured with track Circuit wiring conduits, or with additional guard rail fixtures. A long line method or a short line method can be used to make sleepers; each method has its Advantages and disadvantages [12].

The fundamental reason for any quality control and testing procedure of a manufactured product is to ensure that the product is made to its proper specification.In a particular aspect, this includes a system of inspection and testing during the entir e process of material selection and control and co ntrol of the manufacturing process, right up to th e point of delivery.

The manufacturers should provide the quality certificate of product, the inspection of appearance, thread, internal thread path /Gauge should be carried out before using in factory, sampling volume is $5 \%$ and it can be used after passing the test.

Raw material should have a certificate before using in the factory and the re-inspection of materials should comply with TB10120 and railway Construction (2009) No.152, the unqualified raw materials are not allowed to use. A variety of testing are required in railway sleeper manufacture.These cover three main areas: the tes ting of the basic design in order to confirm its acc eptability, the testing of the materials and the testi ng of the finished product in order to confirm tha $t$ the specification is acceptable. In order to ensure their basic design acceptability, qualification testi $\mathrm{ng}$ is carried out on the first prototype sleepers

These tests varied among authorities, but generally include structural tests with short-term, long-term and repeated loading on the sleeper itself. This typically includes measuring the flexural strength of the section under the rail and that of the sleeper's mid-point, a failure bond test, a torsion test and fatigue testing of the section under the rail seat. [5].

In order to measure pull-out strength, torsion stre ngth, toe load and resistance to side forces, longit udinal creep force and repeated loading, qualifica tion tests are also needed on the fastening assemb ly. Initial qualification tests on the materials and a ggregate and sand that are to be used are also co mmon. Sleeper testing requires that, within the $\mathrm{sp}$ ecification, the finished sleepers hav structural str engths and dimensional properties.

Often a simple structural test is used as part of the acceptance criteria. This is typically a three-point rail seat bending test to ensure that there is no cracking under a specified moment or to record the load at the first apparent crack. This moment or load is usually measured on the assumption that there is some strain in the sleeper's outer fiber[5].

Pre-stressing technology has been developed for many years, and it is divided into pre-tension and post-tension. For concrete railway sleeper, pre-tensioning is widely used where tension is applied to tendons before casting of concrete, as shown in Figure 4. The stages of pre-tensioning are mainly summarized in the following [4]:

(a) Anchoring of tendons against the end abutments.

(b) Placing jacks. 
(c) Applying tension to the wires (HTS) or tendons.

(d) Casting of concrete.

(e) Cutting of the tendons.

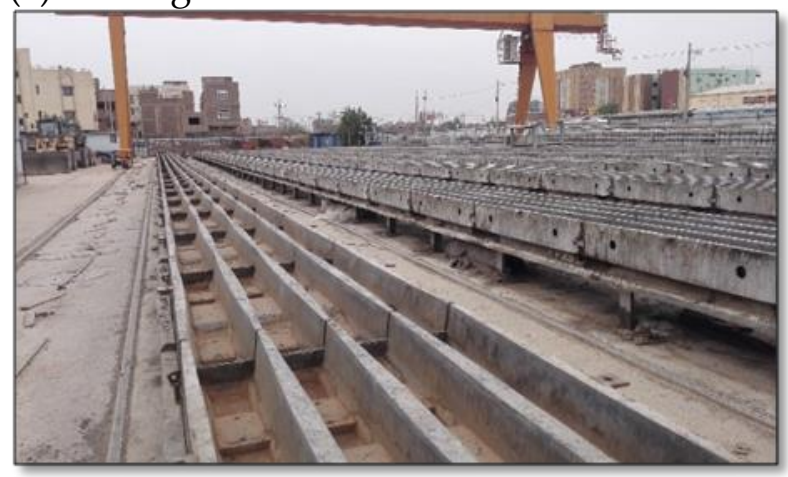

Figure 4. Preparing the frames of the strands.

\section{ANALYSIS OF PRESTRESSED CONCRETE SLEEPERS}

In both theoretical and computational approaches, there are various techniques for modeling concrete structures. Finite Element Analysis (FEA) is a numerical analysis that is commonly applied to complex structures based on the use of materials' nonlinear behavior. [7] Due to the development in knowledge and capability of computer packages and hardware, the use of FEA has increased. Using such flexible FEA kits, any attempt at engineering analysis can be done conveniently and easily. Many of the finite element codes for general purposes have implemented nonlinear material models, i.e. STRAND7, ABAQUS, ANSYS, or MSC. NASTRAN. In nonlinear response analyses, these nonlinear models play a critical role, as each material variable appears to have complex stress-strain behaviors. [8].

Analysis of finite elements (FEA), ANSYS, 15 to include a three-dimensional element (Solid65) with a nonlinear model of concrete-like fragile materials. In a smeared crack analogy for cracking in stress zones, the element features a plasticity algorithm to take the concrete crushing into account in compression zones. It is a solid isoperimetric component with eight nodes with integration points for cracking and crushing controls. [10,11]. A general purpose finite element analysis package, ANSYS15, has produced a three-dimensional nonlinear finite element model of a railway pre-stressed concrete sleeper. The concrete portion was modeled using the solid element of SOLID65 and it is then more feasible to use a truss element, LINK8, for discrete modeling of reinforcement.

\subsection{Materials Properties}

In order to capture the crushing and cracking of sleeper, the most critical parameters should be analyzed such as the maximum tensile stress and strain which can be used to determine crack propagation of sleeper especially in static situation. Because stress and strain relation is relevant to material properties, the properties of concrete and steel used as input data in finite element analysis are given in this section.

(1) Concrete: The railway sleeper is made of concrete material. The typical properties of concrete are mentioned hereunder.

Concrete C50 is used as input data:

$>$ Density: $\rho_{c}=2400 \mathrm{~kg} / \mathrm{m}^{3}$

> Young's modulus: $E_{c=30,200 \mathrm{MPa}}$

Poisson's ratio: $v_{c}=0.2$

Compressive strength: $\mathrm{s}^{\sigma_{c}}=50 \mathrm{MPa}$

Tensile strength: $\sigma_{\text {cts }}=2.85 \mathrm{MPa}$

> Fracture energy: $G_{F G}=154 \mathrm{~N} / \mathrm{m}$

\section{(2) Prestressing Reinforcement:}

As the prestressing tendons are straight (i.e .parallel to the bottom surface) the cross-section can be varied so that the geometry of a particular section may be used to provide pre-stress eccentricity to best match the bending moments, positive or negative. The limit is usually positive rail seat bending moments, while negative center bending moments for broad-gauge sleepers can be even higher. Consequently the typical shape of the sleeper body is tapered from both ends to the centre in height and sometimes width with gentle changes of the sectional profileto prevent stress concentrations.

Typical properties of reinforcement are indicated below;

$>$ Diameter $\boldsymbol{\phi} 7 \mathrm{~mm}$, type of high strength reinforcement.

Density: $\rho_{s}=7.8 \mathrm{~g} / \mathrm{cm}$

> Young's modulus: $E_{s=200 \mathrm{GPa}}$

Poisson's ratio: $v_{s=0.3}$

\section{(3) Prestressed Concrete Sleeper Dimensions:}

In this study, sleeper of type A9P is studied, and detailed dimensions are shown in Figure 5 and Table (I). 


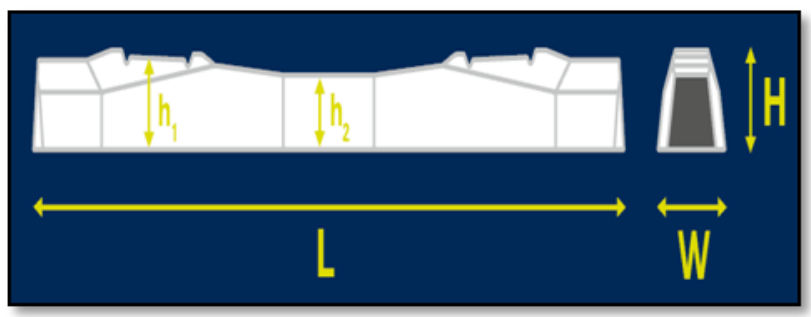

Figure 5. Concrete sleeper dimensions.

TABLE I: PROPERTIES OF PRESTRESSED CONCRETE SLEEPERS.

\begin{tabular}{c|c|c}
\hline \hline No & Description & Value \\
\hline 1 & Axial load & $16.5 \mathrm{~T}$ \\
\hline 2 & Maximum speed & $100 \mathrm{~km} / \mathrm{h}$ \\
\hline 3 & Sleeper length (L) & $2060 \mathrm{~mm}$ \\
\hline 4 & Sleeper height $(\mathrm{H})$ & $228 \mathrm{~mm}$ \\
\hline 5 & Sleeper width (W) & $267 \mathrm{~mm}$ \\
\hline 6 & Concrete grade & $\mathrm{C} 50$ \\
\hline 7 & Concrete volume & $0.083^{\mathrm{m}^{2}}$ \\
\hline 8 & Height of centre sleeper base(h1) & $190 \mathrm{~mm}$ \\
\hline 9 & Height of sleeper centre(h2) & $160 \mathrm{~mm}$ \\
\hline 10 & Weight without fastenings & $210 \mathrm{~kg}$ \\
\hline 11 & Weight with fasteners & $250 \mathrm{~kg}$ \\
\hline 12 & gauge & $1067 \mathrm{~mm}$ \\
\hline 13 & Standard application & Main track sleeper \\
\hline \multicolumn{3}{|c}{}
\end{tabular}

4.2 Static behaviour of railway concrete sleepers The analytical solutions and experimental results of the concrete sleeper due to static hogging moment is illustrated in Figure 6. Figure (6-a) presents the hogging behaviour of the concrete sleeper while Figure (10-b) shows the sagging behaviour of the concrete sleeper. It is found that from Figure (6-a); the numerical results are very close with the experimental result. To obtain the deflection, the static loads of about 126 and 127 $\mathrm{KN}$ are needed, which are, respectively, at $4.5 \%$ and $5.3 \%$ differences from the experimental results. Bending mode of failure is observed for the hogging behaviour. However, the ductility index is slightly above the unity, or on the other hand, the railway concrete sleeper has relatively low ductility. It can be observed from Figure (6-b) that the sagging behaviour causes the sudden failure of the concrete sleeper. Complex mode of failure, combining major shear diagonal cracks and some bending cracks can be detected. It should be noted that for both hogging and sagging behaviors, the first cracks are always due to flexure [8].

From Figure 7 ,it is clear that the tested concrete sleeper fails in bending under hogging moment as shown in Figure (7-a). It is also found that the pre-stressing wires were snapped during the load increment. Figure (7-b) illustrates the failure mode of the tested concrete sleeper under sagging moment. Major shear diagonal cracks can be noticed as well as the crushing of concrete at top fiber, describing the shear-bending failure.
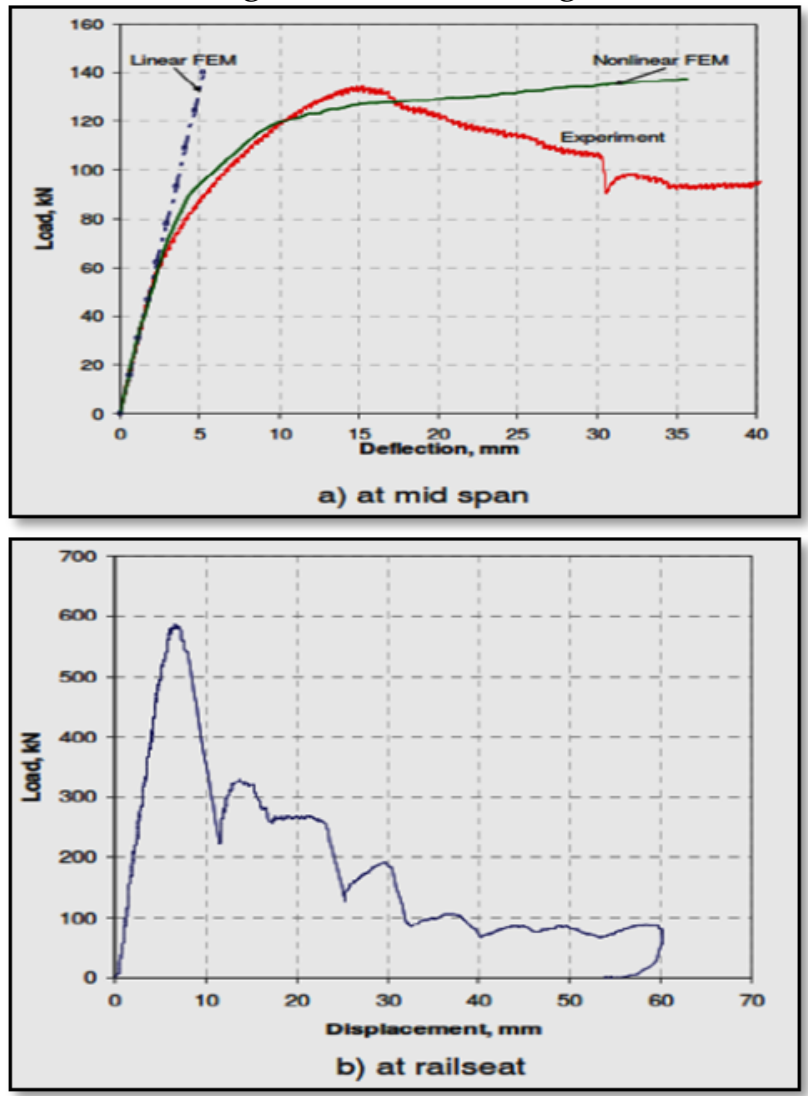

Figure 6. Static behavior of railway concrete sleepers.

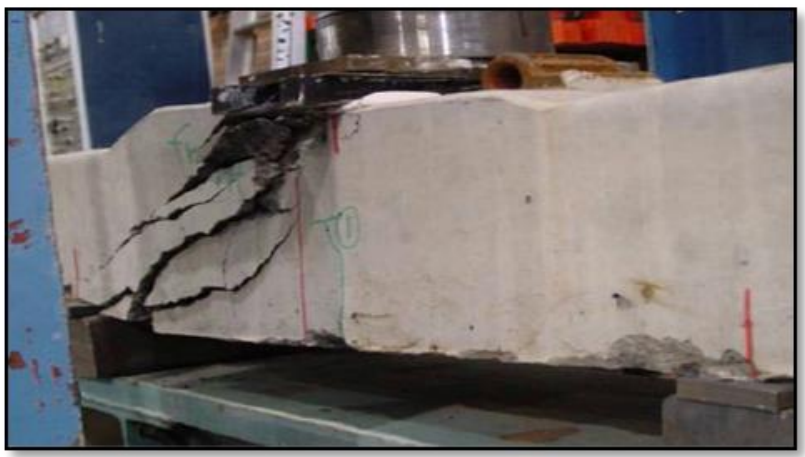

(a) Failure due hogging moment.

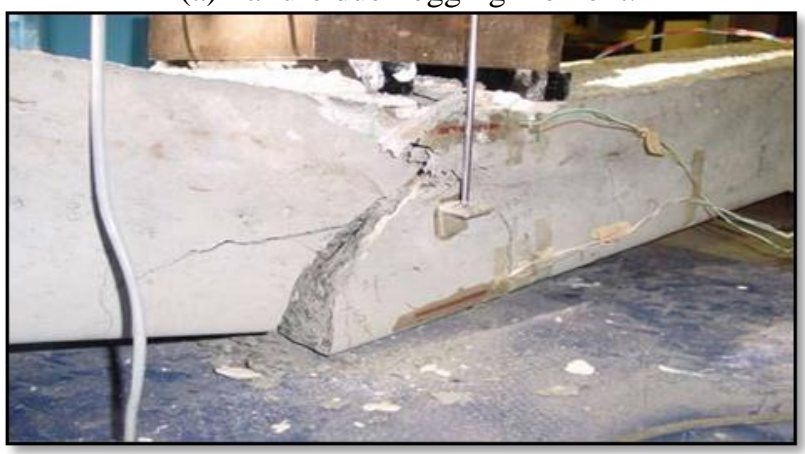

(b) Failure due sagging moment.

Figure 7. Failure modes of railway concrete sleepers.

4.3 Analytical behaviour of railway concrete sleepers ANSYS15 was developed for the non-linear model of a pre-stressed concrete sleeper. The concrete part of the sleeper was modeled using a 
three-dimensional solid element, SOLID65, as illustrated in Figure 8. The concrete is represented by the dedicated solid bricks (SOLID65) and the embedded three-dimensional elements (LINK8) are used as the pre-stressing wires [7]. SOLID65 has eight nodes, each with three degrees of freedom; translations in the directions of nodes $x$, $\mathrm{y}$, and $\mathrm{z}$. This part can predict cracking in tension and crushing in compression. Plastic deformation and creep can also be captured as shown in Figure (9-a). As shown in Figure (9-b), called 'tension cutoff,' the cracking is calculated by the criterion of maximum tensile stress. "Concrete crushes when, as shown in Figure (9-c), the compressive principal stress (von Fails stress) on the failure surface surpasses the" Willam-Warnke. A truss part, LINK8, was used to resist the initial strain and maximum theory elastic strain attributed to pre-stressing forces to simulate the behavior of pre-stressing wires by assuming a perfect bond between these forces. To define reinforcement geometry, material behavior, and pre-stressing strain, LINK8 needs users to input 'true constants.' Notice that neither bending moments nor shear forces can be resisted by this truss feature. The multi-linear stress-strain relationships can alternatively describe the non-linear elastic behavior of concrete.

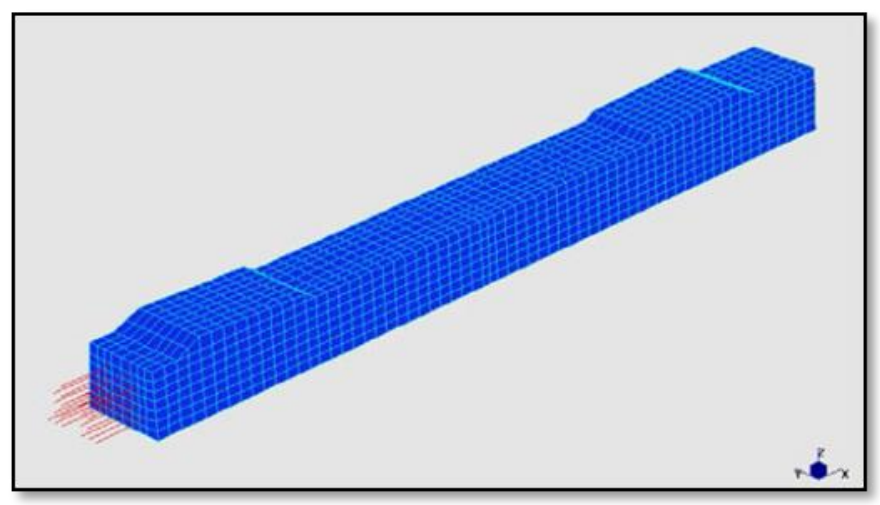

Figure 8. FE model of a railway concrete sleeper.

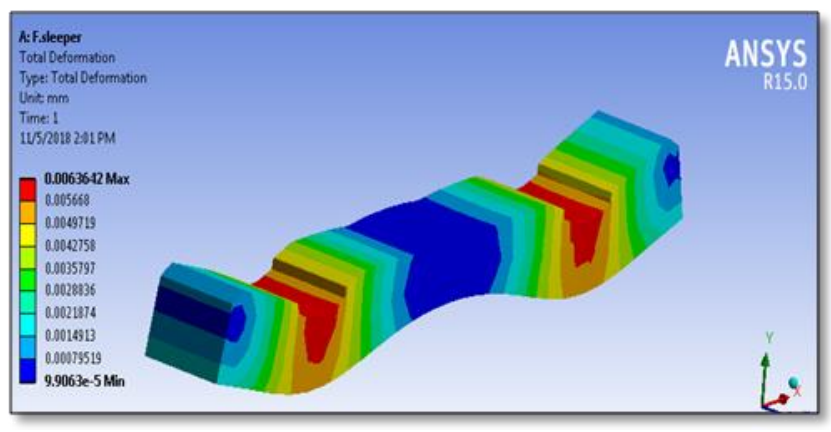

(a) Total deformation.

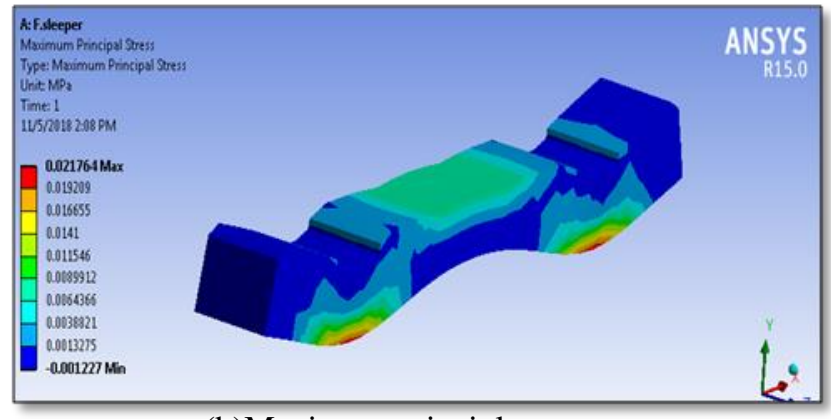

(b)Maximum principle stress.

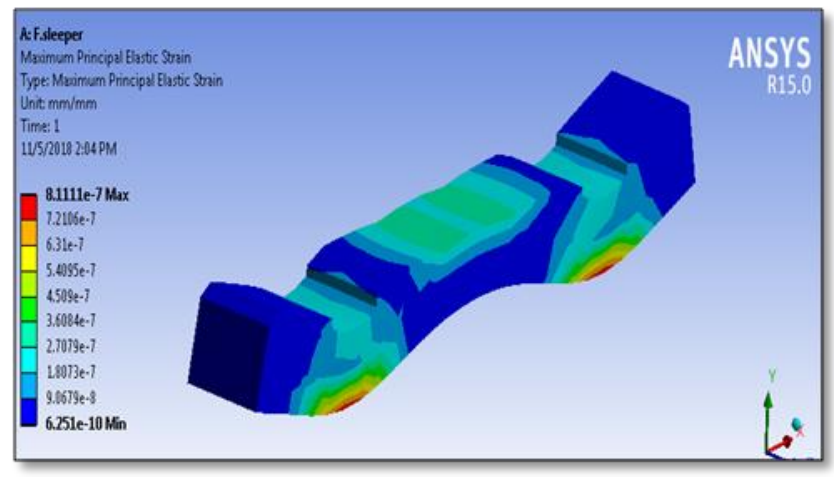

(c)Maximum principle elastic strain.

Figure 9. ANSYS15output of a railway concrete sleeper.

\section{CONCLUSIONS AND RECOMMENDATIONS}

\subsection{Conclusion}

The worldwide use of precast concrete demonstrates that there is worldwide agreement that precast concrete provides the best solution for both high speed and heavy haul track.

This paper presents the advantages of pre-stressed concrete sleepers compared with others which demonstrates long life with time, low maintenance, no damage by white ants or corrosion, minimum creep and low scrap value. In addition the manufacturing is very easy because all materials are available in Sudan and the method of test for sleepers are made according to requirement of the quality control. Also paper demonstrates the finite element modeling to investigate the static behaviors of railway Pre-stressed concrete sleeper by using of nonlinear material properties. Commercial 
package, ANSYS15, was employed in this study, for which it would be benefit for the industry. The sleeper was developed. Then, concrete bricks and pre-stressing wires were modeled using SOLID65 and LINK8 elements, respectively. Most of the results obtained from this program given effective indicator to use pre-stressed concrete sleeper compared to solid concrete element.

\subsection{Recommendations}

The large-scale use of concrete sleepers in railways began in the 1940s. Nowadays they are used successfully all over the world. However, there are still great opportunities to de velop

and extend the use of concrete railway sleepers. S uch progress will be based to a considerable exten $t$ onexperience in countries where concrete sleepe rs have

been in use for a long time, although local conditi ons

in different parts of the world must always be giv en special consideration.

Naturally, as with any product, proper rules and procedures have to be followed throughout the life of the sleeper to ensure that no physical damage takes place.

Sleepers in track are subjected to high repeated loads in an aggressive environment. Thorough and regular maintenance of all parts of the permanent way are necessary to ensure that these loads are kept within acceptable limits and that the relative movement of the ballast and sleeper is minimized to avoid abrasion of the sleeper and ensure full support under the rail seats.

Therefore, forfuture investigations the researchers study the followings;

1- Evaluate the finite element analysis of pre-stressed concrete sleepers under dynamic load (impact) and compare it with experimental study.

2-Study the effect of limit-state design method on pre-stressed concrete sleeper.

3- Study of size of aggregates for optimal performance.

4- Effect of non-metallic fibres.

5- Application of fracture mechanics to quality control of concrete. finite element model of the pre-stressed concrete

6- Alkali-aggregate reaction potential.

7- Sudan Railway Strategic Plan transformation from the narrow gauge to standard gauge. New railway lines encourage the construction of tracks with standard gauges in order to bring Sudan railway transport in line with the development perspective.

\section{REFERENCES}

[1] S. Kaewunruen and A. Remennikov,2008, "Reliability Assessment of Railway Pre-stressed Concrete Sleepers", p.11.

[2] D. K. Kumar and K. Sambasivarao,2014, "Static and Dynamic Analysis of Railway Track Sleeper", No. 6, pp. 662-671, 2014.

[3] C. Library and O. F. Jsce,1999, "A STUDY ON LIMIT-STATE DESIGN METHOD FOR PRESTRESSED CONCRETE SLEEPERS", (Translation from Proceedings of JSCE, No.557/V-34, February 1997)," No. 33, 1999.

[4] J. Taherinezhad, M. Sofi, P. A. Mendis, and T. Ngo,2013, "A Review of Behaviour of Pre-stressed Concrete Sleepers," vol. 13, No. 1, pp. $1-16,2013$.

[5] J. Shimoni and A. Skjelle, 2012, "Concrete railway sleepers".

[6]Shanghai huibo Investment Co.,Ltd (confidential),2011, "Pre-stressed Concrete (with shoulder) Sleepers", QJ/SHIC 09.06-2011.

[7] E. Kahawatta,2018, "Modelling railway pre-stressed concrete sleepers (crossties) with holes and web openings", Procedia Engineering, vol. 161, pp. 1240-1246.

[8] A. Remennikov,2007, "Resistance of railway concrete sleepers to impact loading", No. October, pp. 489-496.

[9] ANSYS, 15, "ANSYS v.15 Documentation Manual", 2012.

[10] Barbosa, A.F., Ribeiro, G.O., 1998, "Analysis of reinforced concrete structures using ANSYS nonlinear concrete Model", In: Idelsohn, S., Onate, E., and Dvorkin, E. (Eds.), Computational Mechanics: New trends and applications, pp. 1-7, 1998.

[11] Padmarajaiah, S.K., Ramaswamy, A., 2002, "A finite element assessment of flexural strength of pre-stressed concrete beams with fiber reinforcement", Cement \& Concrete Composites, vol. 24, pp. 229-241.

[12]http://www.austrak.com/content/production-technology/long-live-vs-sh ort-line/.

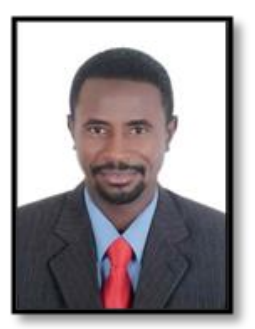

\section{Dr. Ali Hussein Mohamed Ali}

University of Bahri, College of Engineering \& Architecture.

Department of Civil Engineering.

Date of birth: 1971 - Elobeid (N. K. state)

Ph.D in Structural Engineering - Karary University [2011].

M.Sc in Structural Engineering - SUST [2001].

B.Sc in Structural Engineering - SUST [1996].

Major field of study: Civil Engineering [Structures]. 